\title{
Effect of a fruit and vegetable subscription in Danish schools
}

\author{
Karen Eriksen ${ }^{1,2, *}$, Jóhanna Haraldsdóttir ${ }^{2}$, Robert Pederson ${ }^{1}$ and Hanne Vig Flyger ${ }^{1}$ \\ '6 A Day Research Project, Department of Cancer Prevention and Documentation, Danish Cancer Society, \\ Strandboulevarden 49, DK-2 100 Copenhagen, Denmark: ${ }^{2}$ Research Department of Human Nutrition, Royal \\ Veterinary and Agricultural University, Rolighedsvej 30, DK-1958 Frederiksberg C, Copenhagen, Denmark
}

Submitted 19 February 2002: Accepted 15 May 2002

\begin{abstract}
Objective: To measure the effect of a school fruit and vegetable subscription on children's intake of fruit and vegetables after 5 weeks of intervention.

Setting: Seven primary schools in Denmark.

Design and methods: Intervention schools $(n=4)$ were offered a fruit and vegetable subscription comprising one piece per day. Control schools $(n=3)$ situated in another municipality were not offered the subscription. Intake of fruit and vegetables was measured at baseline and 5 weeks after the start of the subscription. Two methods were used for dietary assessment: a pre-coded 24-hour recall form including total food intake and a food-frequency questionnaire (FFQ) including only fruit and vegetables.

Subjects: Children aged $6-10$ years $(n=804$ from intervention schools and $n=689$ from control schools). Response rate in the dietary assessment was 31\%.

Results: At intervention schools $45 \%$ of the children enrolled in the subscription. After 5 weeks of intervention, both subscribers and non-subscribers had increased their intake of fruit by $0.4(P=0.019)$ and $0.3(P=0.008)$ pieces per school day, respectively, but no change was observed in vegetable intake. Total intake increased only for non-subscribers by 0.4 piece/school day $(P=0.008)$, mainly due to the consistent increase in fruit intake. No change in intake was measured at control schools. Only the 24-hour recall questionnaire was sensitive enough to pick up the changes of the subscription, whereas the FFQ was not.

Conclusion: Five weeks with the subscription affected both subscribers and nonsubscribers to increase intake of fruit. This may indicate that the subscription had an additional effect of stimulating parents of non-subscribers to supply their children with fruit. The results stress the importance of evaluating the effect of this type of programme, and the carefulness needed in designing the evaluation study.
\end{abstract}

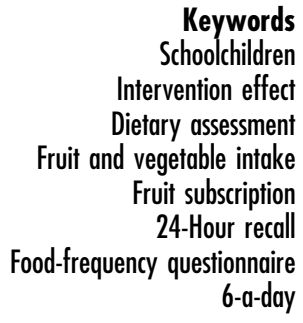

Keywords Schoolchildren Intervention effect Dietary assessment vit subscription 4-Hour recall 6-a-day
A high intake of fruit and vegetables is associated with a reduced risk of cancer and coronary heart disease ${ }^{1-3}$, and several international and national health organisations recommend increasing fruit and vegetable intake ${ }^{4-6}$. In Denmark, the Danish Cancer Society, the Danish Heart Association, the Danish Food Administration and the National Board of Health recommend a daily intake of $600 \mathrm{~g}$ of fruit and vegetables ${ }^{7}$. This is approximately twice the average intake of Danish adults measured in $1995^{\circ}$. To facilitate this recommendation the research project ' 6 a day' was started in 1999 with the aim of identifying and testing methods to improve accessibility of fruit and vegetables. One of the main target groups is children in school settings. In Denmark, most schoolchildren bring their own sandwiches for lunch as no school meals are typically offered. For school-aged children, the main strategy of the 6-a-day project was to improve accessibility of fruit and vegetables in the school through a subscription programme. In this programme children receive a piece of fruit or vegetable every day during the mid-morning break.

The subscription programme was inspired by a similar scheme in Norway, where it has been introduced in 13 of Norway's 19 counties. About 45000 children are expected to take part in the programme during 2001. The goal is that all primary schools in Norway should be invited to join the programme during the coming school year, 2002/03 . In England, as part of the national campaign to improve the diet of children, a new national school fruit programme was started in 2000 and will be implemented nationally by the year 2004. The programme implies that all children in nursery and infant schools ( $4-6$ years) will be entitled to a free piece of fruit every day ${ }^{10}$. These programmes have not yet investigated whether the provision of one piece of fruit will increase the children's total intake. This needs to be studied, as the children might compensate by eating less 
fruit later in the day. The aim of the present study was to investigate whether a fruit and vegetable subscription programme affected the children's total intake of fruit and vegetables.

\section{Methods}

\section{Study design}

The study was set up as a field intervention trial with an intervention group (four schools) and a control group (three schools). Four primary schools, all within the same municipality, accepted the invitation to participate in the pilot project and implement the fruit and vegetable subscription programme. Three control schools were identified in a similar municipality matched by socioeconomic variables: income, education, living conditions and school size. All children at intervention schools were offered the subscription. However, in order to limit the size of the study group, only children from grades $0-3$ (610 years old) were included in the present study. This age group was selected because experiences from Norway showed that younger children were more likely to subscribe than older children?

The effect of the intervention was measured by assessing fruit and vegetable intake at baseline (two weeks before the start of the intervention) and again after 5 weeks of intervention. At intervention schools, intake was measured in all $0-3$ rd grade children, subscribers as well as non-subscribers, and in the control schools in all of the $0-3$ rd grade children. All baseline intake data were collected in the middle of August (2000), subscriptions started at the beginning of September, and intake data were collected again 5 weeks later, in October.

\section{Subscription scheme}

Children and parents were informed of the subscription in a small folder distributed through class teachers. Subscribers received either a piece of fruit or vegetable during the 10 o'clock recess. On Mondays and Wednesdays they received a vegetable, either a small bag of carrots or a small cucumber ( $\sim 80 \mathrm{~g}$ per portion). On Tuesdays and Fridays they received an apple and on Thursdays a second variety of fruit ( $\sim 100 \mathrm{~g}$ per portion). Parents paid a subscription price of 180 DKK/4 months, equivalent to 2 DKK per school day (approximately 0.3 Euro). The actual price was 3.00 DKK per school day, onethird of the price being subsidised by the 6-a-day project.

\section{Intake measurements}

An optically scan-able questionnaire including both a precoded 24-hour recall and a short food-frequency questionnaire (FFQ) was developed for this investigation. The 24-hour recall was developed to measure intake of fruit and vegetables on schooldays and the FFQ to measure intake during a whole month. Portion size was defined as pieces or portions depending on the fruit or vegetable.
Due to limitations in reading and writing skills of the children, parents were asked to help complete the questionnaire.

The questionnaires were handed out in the class and children were asked to take them home for completion, and return them by post. Parents and children were instructed to fill in the questionnaire on a Tuesday, Wednesday, Thursday, Friday or Saturday to ensure that the 24-hour recall only covered weekdays and not weekend days. No attempts were made to remind parents and children to answer and return the questionnaire.

The 24-hour recall part of the questionnaire had a simple design and aimed at covering total intake during the previous day, which always was a weekday (MondayFriday). Two initial questions on the activities of that day served to prompt the child's memory towards that specific day. Subsequently the questionnaire was categorised into six meals: breakfast, mid-morning snack, lunch, afternoon snack, evening meal and evening snack. At each meal the child was asked to tick off the food that was consumed (e.g. bread, meat, drinks, fruit, vegetables, sweets). Quantities were recorded as 'pieces', 'portions' or other units, depending upon the food. This part of the questionnaire aimed at making the children focus on the total intake of the day before and not only on fruit and vegetables. However, in data analysis, only the information on fruit and vegetable intake was included.

The second part of the questionnaire, the food frequencies part, only covered fruit and vegetables. It contained five questions about usual frequency of intake of fruit and vegetables. The questions were phrased 'How often do you eat. .' and the food items were potatoes, raw vegetables, cooked vegetables, fruit and juice. Each item was illustrated by several examples. Response categories were 'Never', '(1-3) times per month', '(1-6) times per week' or ' $(1-5+)$ times per day', giving 15 categories in total. The reference period was the previous month. The FFQ was developed on the basis of short food-frequency questionnaires developed for adults ${ }^{11-14}$.

The validity of the dietary questionnaire was tested in a pilot study in other schools, prior to the investigation. Validity was tested against a 7-day food record in a group of 115 children (aged 6-10 years). Questionnaires were distributed in the same way as described above. Three weeks after completion of the questionnaire, the estimated food record was mailed to the participants. The pre-coded diary was a 7-day consecutive diary including 215 food items distributed between six meals. Quantities were recorded as numbers of pieces or portions, dependent on the type of food. This pre-coded diary has been used in the latest national dietary survey in Denmark ${ }^{8}$. For the 24-hour recall, no systematic differences between the food record and the 24-hour recall were observed for either total fruit and vegetable intake $(P=0.22)$ or vegetable intake $(P=$ 0.38). But for fruit a systematically higher intake was measured with the 24-hour recall compared with the diary 
(difference $0.5 \pm 0.15, P=0.028)$. Validation of the FFQ showed no difference in total intake $(P=0.48)$. But for fruit a systematically higher intake was measured with the questionnaire compared with the diary (difference $0.3 \pm$ $0.11, P=0.008$ ) and for vegetables a systematically lower intake was measured (difference $-0.3 \pm 0.11, P<0.001$ ).

\section{Subjects}

Questionnaires were handed out to all children in grades $0-3$ in intervention schools $(n=804)$ and in control schools $(n=689)$. At baseline, $49 \%$ of children in the intervention schools and $45 \%$ in the control schools returned the questionnaire. At the intervention measurement 5 weeks later, $38 \%$ of the children in intervention schools and $37 \%$ in control schools returned the questionnaire. However, only $31 \%$ of the children returned the questionnaire on both occasions (in intervention schools as well as in control schools). Seventeen questionnaires were excluded due to incomplete information. This left 30\% of the children in the sample for analysis ( $n=240$ and 205, respectively). The response rate was the same for subscribers and nonsubscribers in intervention schools. Further details on the participants are presented in Table 1.

\section{Statistical analysis}

Intake data from the 24-hour recall and FFQ were analysed separately. Two-way analysis of variance (general linear model (GLM)) was used to compare baseline intake in control schools versus intervention schools, and in subscribers versus non-subscribers, with 'group' and 'subscription' as explanatory variables. Data were not normally distributed; therefore data were square-roottransformed before analysis of variance.

The effect of the intervention was defined as the difference in intake between intervention and baseline for each child. A non-parametric test, the Wilcoxon matchedpairs signed-rank sum test, was used to test whether the effect was significantly different from zero, within each group. A non-parametric test was used because not all differences were normally distributed, and square-root transformation did not improve the distribution. The same

Table 1 Children participating in the dietary assessment at intervention schools (subscribers and non-subscribers) and control schools

\begin{tabular}{lccc}
\hline & \multicolumn{2}{c}{ Intervention schools } & \\
\cline { 2 - 3 } & $\begin{array}{c}\text { Subscribers } \\
(n=108)(\%)\end{array}$ & $\begin{array}{c}\text { Non-subscribers } \\
(n=132)(\%)\end{array}$ & $\begin{array}{c}\text { Control } \\
\text { schools } \\
(n=205)(\%)\end{array}$ \\
\hline Boys & 47 & 49 & 45 \\
Girls & 53 & 51 & 55 \\
Grade 0 & 37 & 23 & 27 \\
Grade 1 & 24 & 25 & 28 \\
Grade 2 & 14 & 26 & 18 \\
Grade 3 & 25 & 26 & 28 \\
\hline
\end{tabular}

test (Wilcoxon matched-pairs) was used for further analysis of the 24-hour recall data, where differences in intake, between baseline and intervention, were analysed separately for different meals during the day.

In analysis of the data from the 24-hour recall, subscribers were divided into two groups according to whether a piece of fruit or a piece of vegetable had been served in the subscription programme on the particular day reported in the 24-hour recall. These two groups are referred to as 'fruit days' and 'vegetable days' in the presentation of the results.

Data from the questionnaires were optically scanned and prepared with the program 'Eyes and Hands' (version 4.1). All statistical analyses were conducted with SAS version 6.12 .

\section{Results}

A total of 445 children (aged 6-10 years) participated in the study, 240 from intervention schools and 205 from control schools (Table 1), representing 30\% from the intervention schools and 30\% from the control schools. At intervention schools $45 \%$ of the children in this age group (grades 0-3) subscribed to the fruit and vegetable programme. This was the largest proportion of subscribers, considerably larger than in the higher grades, which are not included in the present study $(35 \%$ in grades $4-6$ and $11 \%$ in grades $7-9$ ).

At baseline there was no difference in intake of fruit or vegetables between the intervention and control schools, or between subscribers and non-subscribers in the intervention schools (Tables 2 and 3). According to the 24-hour recall form, subscribers increased their intake of fruit by 0.4 pieces/school day $(P=0.019)$ on 'fruit days', i.e. when they received fruit as part of the subscription (Table 2A). However, no change in intake of vegetables was observed on 'vegetable days', i.e. when they received vegetables through the subscription (Table $2 \mathrm{~B}$ ), or in total intake when 'fruit and vegetable days' were summed up (Table 2C).

The subscription programme had an additional effect on non-subscribing children at the intervention schools. The fruit intake of non-subscribers increased by 0.3 pieces/ school day $(P=0.008)$ but no change in vegetable intake was observed (Table 2A, B). Non-subscribers also increased their total intake of fruit and vegetables by 0.4 pieces/school day (Table 2C). No difference in intake was measured between baseline and 5 weeks later at control schools (Table 2).

Further analyses of the 24-hour recall data revealed that changes in intake occurred at the different meals during the day. During the morning, including the 10 o'clock fruit break, subscribers' intake of fruit increased by 0.5 pieces/ school day on 'fruit days' $(P<0.001)$ and by 0.4 pieces/ school day of vegetables $(P<0.001)$ on 'vegetable days'. Later during the school day, subscribers tended to eat 
Table 2 24-Hour recall form data. Intakes of fruit (A) and vegetables (B) and total intake (C), at baseline and after 5 weeks of intervention, measured by the 24-hour recall form. Pieces/school day, mean (10th; 50th; 90th percentile)

\begin{tabular}{|c|c|c|c|c|}
\hline & Baseline $†$ & After 5 weeks of intervention & Differenceł & $P$-value§ \\
\hline \multicolumn{5}{|l|}{ A. Fruit intake } \\
\hline \multicolumn{5}{|l|}{ Intervention schools } \\
\hline Subscribers, fruit day $(n=57)$ & $1.3(0.0 ; 1.0 ; 4.0)$ & $1.7(0.0 ; 1.0 ; 4.0)$ & $0.4(-1.0 ; 0.5 ; 2.0)$ & $0.019^{*}$ \\
\hline Subscribers, vegetable day $(n=51)$ & $1.5(0.0 ; 1.0 ; 3.0)$ & $1.4(0.0 ; 1.0 ; 3.0)$ & $-0.1(-2.0 ; 0.0 ; 1.5)$ & 0.716 \\
\hline Non-subscribers $(n=132)$ & $1.4(0.0 ; 1.0 ; 2.5)$ & $1.7(0.0 ; 1.5 ; 3.0)$ & $0.3(-1.0 ; 0.0 ; 2.0)$ & $0.008^{\star \star}$ \\
\hline \multicolumn{5}{|l|}{ Control schools } \\
\hline Control $(n=205)$ & $1.3(0.0 ; 1.0 ; 3.0)$ & $1.3(0.0 ; 1.0 ; 3.0)$ & $-0.0(-2.0 ; 0.0 ; 2.0)$ & 0.933 \\
\hline \multicolumn{5}{|l|}{ B. Vegetable intake } \\
\hline Subscribers: 'fruit day' $(n=57)$ व & $2.1(0.0 ; 2.0 ; 4.0)$ & $1.9(0.0 ; 1.0 ; 5.0)$ & $-0.2(-2.5 ; 0.0 ; 2.0)$ & 0.376 \\
\hline Subscribers: 'vegetable day' $(n=51)$ & $2.1(0.0 ; 1.0 ; 5.0)$ & $2.1(0.0 ; 1.5 ; 4.0)$ & $-0.0(-3.5 ; 0.0 ; 3.0)$ & 0.967 \\
\hline Non subscribers $(n=132)$ & $1.8(0.0 ; 1.0 ; 4.5)$ & $2.0(0.0 ; 2.0 ; 4.5)$ & $0.2(-2.0 ; 0.0 ; 3.0)$ & 0.484 \\
\hline \multicolumn{5}{|l|}{ Control schools } \\
\hline Control $(n=205)$ & $1.9(0.0 ; 1.5 ; 4.0)$ & $1.9(0.0 ; 1.5 ; 4.0)$ & $0.0(-2.0 ; 0.0 ; 2.0)$ & 0.913 \\
\hline \multicolumn{5}{|l|}{ C. Total intake of fruit and vegetables } \\
\hline Subscribers $(n=108) \|$ & $3.6(0.5 ; 3.0 ; 8.0)$ & $3.5(1.0 ; 3.0 ; 7.0)$ & $-0.0(-4.0 ; 0.0 ; 3.0)$ & 0.792 \\
\hline Non-subscribers $(n=132)$ & $3.2(0.0 ; 3.0 ; 3.5)$ & $3.7(1.0 ; 3.5 ; 6.5)$ & $0.4(-2.0 ; 0.5 ; 4.0)$ & $0.008^{\star \star}$ \\
\hline \multicolumn{5}{|l|}{ Control schools } \\
\hline Control $(n=205)$ & $3.1(1.0 ; 3.0 ; 6.0)$ & $3.1(1.0 ; 3.0 ; 6.0)$ & $0.0(-3.0 ; 0.0 ; 2.5)$ & 0.805 \\
\hline
\end{tabular}

† No difference between baseline intake at intervention schools vs. control schools or between subscribers vs. non-subscribers (two-way analysis of variance, GLM).

¥Difference between intervention and baseline measurement for each child.

$\S$ Wilcoxon matched-pairs signed-rank sum test. * $P<0.05 ;{ }^{* \star}, P<0.01$.

If Subscribers were divided into two groups according to whether the subscription had served fruit or vegetable on the school day covered by the 24 -hour recall form: 'fruit day' and 'vegetable day', respectively.

|| For calculating total intake of subscribers, 'fruit day' and 'vegetable day' were summed.

slightly less fruit and fewer vegetables, so the net result was an increase in fruit intake on 'fruit days' but no increase in vegetable intake or in total intake. Nonsubscribers also increased their intake of fruit in the morning by 0.2 pieces/school day $(P=0.015)$ but no change was observed later during the day in the fruit intake. No change in intake of vegetables during the school day was observed for non-subscribers.

The FFQ showed no difference in subscribers' intake between baseline and 5 weeks later, whereas a significant

Table 3 Food-frequency questionnaire data. Intakes of fruit (A) and vegetables (B) and total intake (C), at baseline and after 5 weeks of intervention, measured by the FFQ. Pieces/day, mean (10th; 50th; 90th percentile)

\begin{tabular}{|c|c|c|c|c|}
\hline & Baseline $†$ & After 5 weeks of intervention & Difference & $P$-value $\S$ \\
\hline \multicolumn{5}{|l|}{ A. Fruit intake } \\
\hline \multicolumn{5}{|l|}{ Intervention schools } \\
\hline Subscribers $(n=108)$ & $1.4(0.4 ; 1.0 ; 3.0)$ & $1.5(0.7 ; 1.0 ; 3.0)$ & $0.1(-1.0 ; 0.0 ; 1.0)$ & 0.104 \\
\hline Non-subscribers $(n=132)$ & $1.4(0.3 ; 1.0 ; 3.0)$ & $1.5(0.4 ; 1.0 ; 3.0)$ & $0.1(-1.0 ; 0.0 ; 1.0)$ & 0.054 \\
\hline \multicolumn{5}{|l|}{ Control schools } \\
\hline Control $(n=205)$ & $1.3(0.4 ; 1.0 ; 2.0)$ & $1.4(0.4 ; 1.0 ; 2.0)$ & $0.0(-1.0 ; 0.0 ; 1.0)$ & 0.514 \\
\hline \multicolumn{5}{|l|}{ B. Vegetable intake } \\
\hline Subscribers $(n=108)$ & $1.6(0.5 ; 1.1 ; 3.0)$ & $1.5(0.5 ; 1.4 ; 3.0)$ & $-0.1(-1.1 ; 0.0 ; 1.0)$ & 0.229 \\
\hline Non-subscribers $(n=132)$ & $1.6(0.3 ; 1.3 ; 2.9)$ & $1.6(0.4 ; 1.3 ; 3.0)$ & $0.0(-1.0 ; 0.0 ; 1.0)$ & 0.715 \\
\hline \multicolumn{5}{|l|}{ Control schools } \\
\hline Control $(n=205)$ & $1.4(0.4 ; 1.3 ; 2.6)$ & $1.4(0.4 ; 1.1 ; 2.6)$ & $-0.0(-1.0 ; 0.0 ; 1.0)$ & 0.801 \\
\hline \multicolumn{5}{|c|}{$\begin{array}{l}\text { C. Total intake of fruit and vegetables } \\
\text { Intervention schools }\end{array}$} \\
\hline Subscribers $(n=108)$ & $3.0(1.3 ; 2.6 ; 5.3)$ & $3.0(1.4 ; 2.6 ; 5.1)$ & $-0.0(-1.6 ; 0.0 ; 1.4)$ & 0.737 \\
\hline Non-subscribers $(n=132)$ & $2.9(1.0 ; 2.6 ; 5.1)$ & $3.1(1.0 ; 3.0 ; 6.0)$ & $0.2(-1.1 ; 0.1 ; 1.3)$ & $0.046^{*}$ \\
\hline \multicolumn{5}{|l|}{ Control schools } \\
\hline Control $(n=205)$ & $2.7(1.1 ; 2.5 ; 4.7)$ & $2.7(1.1 ; 2.7 ; 4.3)$ & $0.0(-1.6 ; 0.0 ; 1.3)$ & 0.319 \\
\hline
\end{tabular}

†No difference between baseline intake at intervention schools vs. control schools or between subscribers vs. non-subscribers (two-way analysis of variance, GLM).

$\ddagger$ Difference between intervention and baseline measurement for each child.

$\S$ Wilcoxon matched-pairs signed-rank sum test. * $P<0.05$ 
increase was observed for non-subscribers ( 0.1 pieces/ day, $P=0.046$ ). No difference in intake was observed at control schools (Table 3).

\section{Discussion}

This is, as far as we are aware, the first study to report the quantitative effect of a fruit and vegetable subscription programme in primary schools. The results show that a programme where subscribers received a piece of fruit or vegetable during the school day increased the fruit intake of both subscribers and non-subscribers.

The expected effect of the present programme was one piece of fruit or vegetable per school day, equal to the piece of fruit or vegetable in the subscription. The effect observed for subscribers was only 0.4 pieces/school day for fruit and no effect for vegetables or total intake (fruit and vegetables). This indicates that the fruit and vegetables provided in the programme replaced some of the fruit and vegetables eaten at other times of the day, resulting in no change in total intake. Further analyses of the 24-hour recall data divided into meals confirmed this. This emphasises the need for evaluating fruit and vegetable interventions in terms of their effect on total intake, including potential compensation during the rest of the school day and during weekends.

An unexpected effect of the subscription programme was that non-subscribers also increased their intake of fruit. This effect was observed with both the 24-hour recall and the FFQ. This might be explained by an increased awareness of the importance of eating fruit and vegetables at the intervention schools. All children were offered the subscription and therefore the families had to discuss and decide if they wanted to subscribe the child or not. In Denmark, parents feel strongly that it is their responsibility to provide food for their child in school $^{15}$ as no school meals are offered. The subscription scheme may have encouraged parents of non-subscribers to take extra responsibility and supply their children with fruit themselves, not only on schooldays but also during the weekend. The social implications of the 'fruit break', where children and teachers gathered to eat fruit/ vegetables, may have also stimulated non-subscribers to bring fruit every day.

The fact that only the fruit intake was affected by the subscription scheme for both subscribers and nonsubscribers indicates that it is easier to increase children's fruit intake than vegetable intake. Subscribers received vegetables on some of the days as part of the subscription scheme. Subscribers failed to increase their vegetable and total intakes, whereas non-subscribers increased their total intake mainly due to the consistent increase in fruit intake. Parents of non-subscribers are more likely to provide their children with a piece fruit instead of vegetables. Fruit is basically 'ready to eat' direct from the supermarket, whereas vegetables often require preparation before they can be eaten. However, it is important to promote both fruit and vegetables, as both have a beneficial effect in disease prevention. It is therefore important to find ways to increase children's vegetable intake as well as fruit intake, and future programmes should take effort to achieve this.

The observed increase in fruit intake of 0.4 pieces/day is comparable with other intervention studies where the aim has been to increase intake of fruit and vegetables. In the USA, the National Cancer Institute has financed a number of interventions under the "5-a-day for better health programme ${ }^{, 16-18}$. These programmes have included education programmes, parent involvement and improving the fruit and vegetable servings in school food services. These programmes have attained increases in total intake ranging from 0.2 pieces/day ${ }^{19}$ to 1.7 pieces/ day $^{20}$. Other intervention programmes have aimed at improving not only fruit and vegetable intakes but also the whole diet and physical activity ${ }^{21-23}$. Only one of these programmes has attained a significant increase in fruit and vegetable intake $(0.36 \text { pieces/day })^{21}$. Compared with these multi-component interventions, it is remarkable that a simple and more cost-efficient intervention like the subscription programme described in this study is capable of changing children's intake.

Only the 24-hour recall instrument was adequately sensitive to detect the effect of the intervention among subscribers, whereas the food-frequency questionnaire detected no change. This had already been anticipated while planning the study design, and the 24-hour method was chosen as the primary instrument and the FFQ for supplementary information. The basic principle of all FFQs, to ask about 'usual' frequencies of intake, implies that it may be difficult to detect small changes in the daily pattern of intake by this method. Furthermore, 'usual' intake reported in FFQs includes weekends as well as weekdays, and increases in intake during schooldays would be 'diluted' by unaltered intake during the weekends, thus making changes more difficult to detect. The observed result that the subscription fruit was not just an extra intake, but partly replaced other fruit otherwise eaten later in the day, further explains why it was not possible to detect this change by the FFQ method but only by the more detailed 24-hour recall approach. Originally the FFQ method was developed to measure average intake over a given period of time, typically a year ${ }^{24}$. In the present investigation the reference period was defined as one month because there was only a 5-week interval between the baseline and the intervention measurement. Although simple FFQs have been used to measure longterm changes in intake ${ }^{12-14}$, they are hardly suited for evaluating the quantitative effect of an intervention programme, and therefore other methods like the 24hour recall should be considered.

The fact that both subscribers and non-subscribers increased their fruit intake emphasises the importance of 
using control groups that are not affected by the intervention for evaluation purposes. In the present study, control schools were situated in a different municipality where no subscription programme had been offered.

The response rate $(31 \%)$ in the present study was low. Similar response rates have been reported from other studies where questionnaires were sent out without prior arrangements with the participants ${ }^{25-27}$. The response rate might have been improved by sending reminders to nonresponding families, but this was not possible due to the arrangements with the schools. The low response rate implies a risk for a selective investigation group, as responders are often more healthy and have a higher socio-economic status than non-responders ${ }^{28-32}$. It is possible that the present study includes a larger proportion of children with high intake of fruit and vegetables at baseline. It is therefore likely that children with a high baseline intake of fruit and vegetables are over-represented in the present study. Whether a similar effect of the programme would be observed in a group including low consumers remains to be answered.

This study evaluates the effect of the subscription programme on a short-term basis only ( 5 weeks). Whether this effect will be strengthened or will decline with time, as reported from some studies ${ }^{20,33}$, remains unanswered. A particularly interesting question is whether the increased fruit intake of non-subscribers in the long-term context will be sustained to the same extent as in subscribers.

\section{Conclusions}

Introduction of the fruit and vegetable subscription programme increased fruit intake, not only among subscribers but also among non-subscribers. Therefore, this type of programme may have a wider effect than expected. The results of this study highlight the need for evaluating the total daily effect of such intervention programmes; in particular, there seems to be evidence that children may compensate for fruit/vegetables provided at school later in the day. The results also highlight two crucial aspects in designing evaluation of intervention studies: the importance of a control group that is entirely unaffected by the intervention, and the importance of choosing a dietary assessment method that is sensitive enough to detect small changes in intake.

\section{References}

1 van't Veer P, Jansen MC, Klerk M, et al. Fruits and vegetables in the prevention of cancer and cardiovascular disease. Public Health Nutr. 2000; 3: 103-7.

2 Block G, Patterson B, Subar A. Fruit, vegetables, and cancer prevention: a review of the epidemiological evidence. Nutr. Cancer 1992; 18: 1-29.

3 Ness AR, Powles JW. Fruit and vegetables, and cardiovascular disease: a review. Int. J. Epidemiol. 1997; 26: 1-13.
4 Foerster SHJ, Di Sogra LK, Pivonka E. The national 5 a day for better health program: an American nutrition and cancer initiative. In: Wheelock V, ed. Implementing Dietary Guidelines for Healthy Eating. London: Chapman \& Hall, 1997; 447-79.

5 Statens Ernæringråd. Recommendations for Increased Intake of Fruit and Vegetables [in Norwegian] Oslo: Statens Ernæringråd, 1996.

6 Williams C. Healthy eating: clarifying advice about fruit and vegetables [published erratum appears in Br. Med. J. 1995; 310: 1665]. Br. Med.J. 1995; 310: 1453-5.

7 Trolle E, Fagt S, Ovesen L. Fruit and Vegetables, Recommendations for Intake [in Danish]. Publication No. 244. Copenhagen: Veterinær og Fødvaredirektoratet (Danish Veterinary and Food Administation), 1998.

8 Andersen D, Fagt S, Groth MV, et al. Danish Dietary Habits 1995, Main Results [in Danish with an English summary]. Publication No. 235. Copenhagen: Levenedsmiddelstyrelen (National Food Agency), 1996.

9 National Council on Nutrition and Physical Activity, Norwegian Fruit and Vegetable Marketing Board. School Participation, Who Participates [online]. Available at http:// www.skolefrukt.net/fakta/fakta_eng.html. Accessed February 2002.

10 Department of Health. The National School Fruit Scheme [online]. Available at http://www.doh.gov.uk/schoolfruit scheme/. Accessed February 2002.

11 Serdula M, Coates R, Byers T, et al. Evaluation of a brief telephone questionnaire to estimate fruit and vegetable consumption in diverse study populations. Epidemiology 1993; 4: 455-63.

12 Smith-Warner SA, Elmer PJ, Fosdick L, et al. Reliability and comparability of three dietary assessment methods for estimating fruit and vegetable intakes. Epidemiology 1997; 8: 196-201.

13 Thompson B, Demark-Wahnefried W, Taylor G, et al. Baseline fruit and vegetable intake among adults in seven $5 \mathrm{a}$ day study centers located in diverse geographic areas. J. Am. Diet. Assoc. 1999; 99: 1241-8.

14 Haraldsdottir J, Holm L, Astrup A, et al. Monitoring of dietary changes by telephone interviews: results from Denmark. Public Health Nutr. 2001; 4: 1287-95.

15 Andersen D, Hestbæk AD. Responsibility and Values in Danish Families [in Danish]. Copenhagen: Socialforskningsinstitutet (The Danish National Institute of Social Research), 1999.

16 Davis M, Baranowski T, Resnicow K, et al. Gimme 5 fruit and vegetables for fun and health: process evaluation. Health Educ. Behav. 2000; 27: 167-76.

17 Reynolds KD, Franklin FA, Leviton LC, et al. Methods, results, and lessons learned from process evaluation of the high 5 school-based nutrition intervention. Health Educ. Behav. 2000; 27: 177-86.

18 Story M, Mays RW, Bishop DB, et al. 5-a-day Power Plus: process evaluation of a multicomponent elementary school program to increase fruit and vegetable consumption. Health Educ. Behav. 2000; 27: 187-200.

19 Baranowski T, Davis M, Resnicow K, et al. Gimme 5 fruit, juice, and vegetables for fun and health: outcome evaluation [published erratum appears in Health Educ. Behav. 2000; 27: 390]. Health Educ. Behav. 2000; 27: 96-111.

20 Reynolds KD, Franklin FA, Binkley D, et al. Increasing the fruit and vegetable consumption of fourth-graders: results from the high 5 project. Prev. Med. 2000; 30: 309-19.

21 Gortmaker SL, Cheung LW, Peterson KE, et al. Impact of a school-based interdisciplinary intervention on diet and physical activity among urban primary school children: eat well and keep moving. Arch. Pediatr. Adolesc. Med. 1999; 153: $975-83$.

22 Manios Y, Moschandreas J, Hatzis C, et al. Evaluation of a 
health and nutrition education program in primary school children of Crete over a three-year period. Prev. Med. 1999; 28: $149-59$.

23 Nader PR, Stone EJ, Lytle LA, et al. Three-year maintenance of improved diet and physical activity: the CATCH cohort. Child and Adolescent Trial for Cardiovascular Health. Arch. Pediatr. Adolesc. Med. 1999; 153: 695-704.

24 Willett WC, Lenart E. Reproducibility and validity of foodfrequency questionnaires. In: Willett WC, ed. Nutritional Epidemiology. Oxford: Oxford University Press, 1998; 101-47.

25 Wheeler C, Rutishauser I, Conn J, et al. Reproducibility of a meal-based food frequency questionnaire. The influence of format and time interval between questionnaires. Eur.J. Clin. Nutr. 1994; 48: 795-809.

26 Radimer KL, Harvey P, Lytle L. Correspondence of selfreported fruit and vegetable intake with dietary intake data. Aust. N.Z. J. Public Health 1997; 21: 703-10.

27 Field AE, Peterson KE, Gortmaker SL, et al. Reproducibility and validity of a food frequency questionnaire among fourth to seventh grade inner-city school children: implications of age and day-to-day variation in dietary intake. Public Health Nutr. 1999; 2: 293-300.
28 Bergstrand R, Vedin A, Wilhelmsson C, et al. Bias due to nonparticipation and heterogeneous sub-groups in population surveys. J. Chronic Dis. 1983; 36: 725-8.

29 Sonne-Holm S, Sorensen TI, Jensen G, et al. Influence of fatness, intelligence, education and sociodemographic factors on response rate in a health survey. J. Epidemiol. Community Health 1989; 43: 369-74.

30 Jackson R, Chambless LE, Yang K, et al. Differences between respondents and nonrespondents in a multicenter community-based study vary by gender ethnicity. The Atherosclerosis Risk in Communities (ARIC) Study Investigators. J. Clin. Epidemiol. 1996; 49: 1441-6.

31 Hill A, Roberts J, Ewings P, et al. Non-response bias in a lifestyle survey. J. Public Health Med. 1997; 19: 203-7.

32 Lerman Y, Shemer J. Epidemiologic characteristics of participants and nonparticipants in health-promotion programs. J. Occup. Environ. Med. 1996; 38: 535-8.

33 Nicklas TA, Johnson CC, Myers L, et al. Outcomes of a high school program to increase fruit and vegetable consumption: Gimme 5 - a fresh nutrition concept for students. J. Sch. Health 1998; 68: 248-53. 